\title{
Rastreando las críticas de Finnis al punto de vista interno de Hart: inestabilidad y el "sentido y propósito" de la acción humana en el derecho
}

\author{
Tracing Finnis's Criticism of Hart's Internal Point \\ of View: Instability and the 'Point' of Human \\ Action in Law $^{*}$ \\ Verónica Rodríguez-Blanco**
}

Recepción: 03/12/2019

Evaluación: 23/12/2019

Aceptación final: 11/03/2020

\begin{abstract}
Resumen: Finnis nos dice que el participante de la práctica jurídica, por ejemplo, el ciudadano, el juez, el abogado, están comprometidos con el derecho y están interesados en distinguir entre una norma buena y una no tan buena, entre una directiva justa y una directiva injusta, entre una decisión racional de un tribunal y una decisión irracional. El punto de vista interno de Hart se niega a hacer ulteriores distinciones entre los casos centrales y periféricos del derecho y esto trae inestabilidad al concepto. El punto de vista interno de Hart como inestable puede remontarse a una crítica más fundamental, a saber, el punto de vista interno de Hart no puede ser usado
\end{abstract}

* Traducción del inglés de Nelson Tepedino y Gabriela Scataglini.

** Catedrática de Filosofía Política, Moral y Legal, Centro de Filosofía del Derecho, University of Surrey, Guildford, Reino Unido. Correo electrónico: v.rodriguez-blanco@surrey.ac.uk. El material de este trabajo se basa en mi artículo "Tracing Finnis's criticism of Hart's Internal Point of View: Instability and the 'Point' of Human Action in Law", en The Cambridge Companion to Legal Positivism, Cambridge University Press, 2021. Mi profundo agradecimiento a Nelson Tepedino y Gabriela Scataglini por la cuidadosa traducción del presente texto. 
para entender el sentido y propósito de las acciones humanas y, por lo tanto, no podemos basarnos en el punto de vista interno de Hart para identificar diferencias de importancia que pueda hacer cualquier actor en el campo. En la literatura sobre la "metodología", este argumento de la inestabilidad es pasado por alto y sus premisas no han sido cuidadosamente examinadas. En este capítulo, trataré de mostrar que la idea de que el punto de vista interno es inestable es, a la vez, clave para entender los límites de la teoría del derecho de Hart y para arrojar más luz sobre la idea de que el derecho debe concebirse en términos de un caso central o focal.

Palabras clave: metodología de la filosofía del derecho, caso focal o central, teorías de la acción, Finnis, Anscombe, H. L. A. Hart.

\begin{abstract}
Finnis, tells us, that the participant of the legal practice, e.g. the citizen, the judge, the lawyer, are engaged with the law and are interested in distinguishing between a good and a not so good norm, between a just directive and unjust directive, between a rational court-decision and a non-rational court decision. Hart's internal point of view refuses to make further distinctions between the peripheral and central cases of law and this brings instability to the concept. Hart's internal point of view as unstable can be traced to a more fundamental criticism, i.e. Hart's internal point of view cannot be used to understand the point of human actions and therefore we cannot rely on Hart's internal point of view to identify significance differences that any actor in the field can make. In the 'methodology' literature, this argument on instability is overlooked and its premises has not been carefully examined. In this chapter, I will try to show that the idea that the internal point of view is unstable is both key to understand the limits of Hart's legal theory and shed further light on the view that law should be conceived in terms of a central or focal case.
\end{abstract}

Keywords: methodology in legal philosophy, central case or focal meaning, theories of action, Finnis, Anscombe, H.L.A. Hart. 
Rastreando las críticas de Finnis al punto de vista interno de Hart: inestabilidad...

\section{Introducción}

Mucha tinta se ha vertido en torno al punto de vista interno de Hart $^{1}$ y su rol para comprender y definir la así llamada regla del reconocimiento. Sorprendentemente, no ha habido muchos intentos de sacar a la luz y desarrollar más ampliamente la crítica planteada por Finnis de que el punto de vista interno de Hart es inestable. Finnis está de acuerdo con Raz y Hart en que la perspectiva interna es clave para dilucidar el carácter del derecho. Sin embargo, plantea que el punto de vista interno de Hart no puede hacer el trabajo que pretende debido a su inestabidad. Finnis añade entonces que existe un remedio para esta inestabilidad, a saber, que el derecho debe ser entendido desde el punto de vista del agente que posee razón práctica. Me explico.

Finnis (y hasta cierto punto también Dworkin) propone una metodología en la cual el punto de vista práctico nos hace posible identificar y determinar la materia de la teoría del derecho. No obstante, a diferencia de Dworkin, Finnis reconoce que existen hechos tanto sociales como evaluativos que juegan un importante rol en cualquier aproximación descriptivo-explicativa. Finnis defiende la visión de que cualquier descripción y explicación de lo que sea el derecho debería hacerse desde el punto de vista del hombre que posee razonabilidad práctica. ${ }^{2}$ En otras palabras, la razonabilidad práctica nos permite entender las cualidades únicas del derecho y las formas en las cuales puede ayudar a alcanzar los bienes básicos en nuestras vidas. ¿Cómo reconcilia Finnis un método descriptivo-explicativo y la idea de que existe un punto de vista privilegiado - que es el punto de vista de la razonabilidad práctica- sin caer en la versión fuerte de la teoría del derecho normativa defendida por Ronald Dworkin (1986)?

Finnis recurre a la idea aristotélica, desarrollada más tarde por Tomás de Aquino y los escolásticos medievales, de un significado "focal" o de un caso "central", que es la idea de que el caso central de derecho es la concepción del derecho defendida por el hombre que posee razonabilidad

1 En los últimos diez años ha habido un importante cuerpo de literatura que discute la idea de Hart sobre el "punto de vista interno". Veáse Shapiro (2006; 2000); Coleman (2001); Zipursky (2006); Perry (2006; 1995; 2000); Patterson (1999); Schauer (1994); Adler (2009); Holton (1998).

2 "Razonabilidad práctica" es el término introducido por Finnis (2011, capítulo V). 
práctica. ${ }^{3}$ Finnis argumenta que esta metodología permite a los teóricos diferenciar los sistemas jurídicos defectuosos o marginales de aquellos que se aproximan a los ideales de la justicia. En otras palabras, multiplicidad y unificación pueden reconciliarse porque tanto la creencia común como la aproximación iuspositivista de que los sistemas jurídicos perversos son derecho, junto con la opinión de que el derecho sirve a los ideales de la justicia, pueden ser unificadas coherentemente.

Finnis está siguiendo la intuición de Aristóteles: para Aristóteles una exitosa crítica de la teoría de las formas de Platón necesita mostrar que existe la multiplicidad, pero también la unidad, en conceptos clave tales como el "ser", el "bien", la "democracia", etc. El punto de vista del hombre que posee razonabilidad práctica, nos dice Finnis, explicará por qué consideramos que los sistemas jurídicos que no poseen características deseables, tales como la búsqueda del bien común, son derecho. Más aún, el teórico será simultáneamente capaz de explicar por qué consideramos derecho sistemas que abrazan los ideales de justicia. Si el argumento de Finnis resulta exitoso, en contraposición a la fuerte jurisprudencia normativa de Dworkin, podría ser un camino fructífero para responder la pregunta principal acerca de la jurisprudencia sustantiva, a saber, qué es el derecho.

Las afirmaciones metodológicas de Finnis son intrigantes y complejas porque uno puede identificar dos aspectos en su metodología: un aspecto explicativo y uno práctico. El primer aspecto supone una metodología descriptivo-explicativa; esto significa que apunta en la dirección de describir conceptos jurídicos, pero cree que la descripción no puede tener lugar sin considerar el caso central de la teoría del derecho: el punto de vista del hombre que posee razonabilidad práctica. De acuerdo con esta visión, el teórico necesita explicar y describir tanto los casos marginales como el caso nuclear del derecho, tal como son concebidos por el punto de vista práctico. Esta tarea no puede hacerse, sin embargo, sin tomar en cuenta el punto de vista del participante, esto es, el punto de vista del hombre que tiene hábitos, prácticas sociales, valores, intenciones y creencias dentro de una comunidad dada. Finnis enfatiza el rol de la antropología, el análisis estadístico, etc., para expandir la comprensión del punto de vista del participante. Sin 
Rastreando las críticas de Finnis al punto de vista interno de Hart: inestabilidad...

embargo, nos dice que tales datos solo nos ayudan a entender los grados de perfección o imperfección del punto de vista práctico y los principios de la razonabilidad práctica en culturas y prácticas sociales diferentes. La tarea del intelecto es aprehender qué es razonable prácticamente. ${ }^{4}$ En otras palabras, lo que es razonable prácticamente no puede derivarse de los datos empíricos de la naturaleza humana y la formación de un concepto depende de la aprehensión del punto de vista práctico del hombre.

Por otra parte, Finnis rechaza la idea de Dworkin de que nuestro punto de partida deberían ser nuestras propias creencias morales y políticas, dado que de acuerdo con Finnis esas creencias pueden ser falsas o estar afectadas por nuestros prejuicios. Necesitamos situarnos fuera de esas creencias y revisarlas en orden a llegar a las razones "correctas".

Para Dworkin, por el contrario, la pregunta práctica necesita ser respondida en términos de una pregunta teórica: lo que debo hacer requiere una respuesta a la pregunta acerca de lo que debo creer sobre los fundamentos del derecho. El profesional, el juez, el legislador y el abogado necesitan comprometerse en una investigación sobre los fundamentos del derecho que hacen verdaderas las proposiciones jurídicas, y esta búsqueda es una tarea constructiva que nos exige tener en cuenta las convicciones morales

4 Finnis lo expresa como sigue: "El conocimiento descriptivo puede ocasionar una modificación de los juicios de importancia y significación con los cuales el teórico se aproxima por primera vez a sus datos y puede sugerir una reconceptualización. Pero el conocimiento no se habrá alcanzado sin una conceptualización preliminar y, por lo tanto, un conjunto de principios de selección y relevancia derivados de algún punto de vista práctico... Los problemas metodológicos de la formación de conceptos, tal como los hemos rastreado en este capítulo, nos obligan a reconocer que el punto de equilibrio reflexivo en la ciencia social descriptiva solo puede ser alcanzado por alguien en quien un amplio conocimiento de los datos y una comprensión penetrante de las preocupaciones y puntos de vista prácticos de otros hombres estén ligados a una metodología sólida sobre todos los aspectos de la maduración humana genuina y de una auténtica razonabilidad práctica” (2011. pp. 17-18).

5 Finnis afirma: "Así como no se trata de derivar los juicios básicos sobre los valores humanos y los requisitos de la razonabilidad práctica mediante alguna inferencia de los hechos de la situación humana, tampoco se trata de reducir la ciencia social descriptiva a una apología de la ética o de los juicios políticos propios, o a un proyecto para distribuir elogios o culpas entre los actores de la escena humana: en este sentido, la ciencia social descriptiva está libre de valores"' (2011, p 17). Ver también Finnis (1987). Para una crítica de la metodología de Dworkin como una incapacidad para ver la importancia de la razón práctica, ver mi artículo (Rodríguez-Blanco, 2016b). 
del profesional y del teórico. ${ }^{6}$ Es cierto: es su integridad la que guiará al profesional en la tarea de construir la mejor interpretación posible de lo que es derecho y la exigencia de ajustarse al volumen del material jurídico lo capacitarán para alcanzar un balance entre la solidez moral y el precedente judicial. Pero es una empresa teóricamente justificativa, que se caracteriza por determinar los fundamentos del derecho.

El segundo aspecto de la metodología de Finnis es el de tipo práctico. En el núcleo de la indagación de Finnis está la pregunta práctica acerca de lo que uno debe hacer de acuerdo con los principios de la razonabilidad práctica. Para Finnis, el teórico necesita explicar el punto de vista práctico, pero una vez que el punto de vista práctico ha sido identificado, este nos afecta a todos: al teórico y al participante. Es porque el punto de vista práctico incide sobre todos nosotros que tenemos que actuar conforme a los principios de la razonabilidad práctica, y el derecho necesita que se le dé forma de acuerdo tanto a dichos principios como también a los valores básicos. Desde el punto de vista del teórico, de acuerdo con Finnis, la tarea explicativa precede la tarea justificativa. Sin embargo, existe una interdependencia mutua entre las empresas explicativa y justificativa. La deliberación práctica requiere conocimiento de la situación humana, pero al mismo tiempo la evaluación desde el punto de vista del hombre que

6 Ronald Dworkin afirma en varios pasajes de El imperio del derecho que la tarea interpretativa requiere las convicciones sustantivas del teórico y del juez en orden a determinar cuál interpretación se ajusta mejor a los materiales jurídicos del pasado y es moralmente sólida: "Las teorías interpretativas de cada juez están fundamentadas en sus propias convicciones sobre el 'punto' - el propósito justificativo u objetivo o principio— de la práctica legal como un todo, y esas convicciones serán inevitablemente diferentes, al menos en detalle, de las de otros jueces" (1986, pp. 87-88). Dworkin explica el rol de las convicciones como sigue: "Ahora podemos mirar atrás a través de nuestra consideración analítica para componer un inventario del tipo de convicciones o creencias o asunciones que alguien necesita para interpretar algo. Necesita asunciones y convicciones sobre lo que cuenta como parte de la práctica en orden a definir los datos en bruto de su interpretación en la etapa pre-interpretativa; la actitud interpretativa no puede sobrevivir a menos que los miembros de la misma comunidad interpretativa compartan al menos aproximadamente las mismas asunciones sobre esto... Finalmente, necesitará más convicciones sustantivas sobre cuáles tipos de justificación realmente mostrarían la práctica en la mejor luz" (1986, p. 67). 
Rastreando las críticas de Finnis al punto de vista interno de Hart: inestabilidad...

posee razonabilidad práctica determina qué descripciones son esclarecedoras y significativas. ${ }^{7}$

El concepto de derecho, nos dice Finnis, se utiliza de diferentes maneras y en diferentes contextos. Sin embargo, a pesar de su multiplicidad, "derecho" se refiere a un solo concepto, y en consecuencia las diferentes concepciones del derecho se refieren a una fuente primaria, la cual es el punto de vista del hombre que posee razonabilidad práctica. Por lo tanto, su argumento muestra que la multiplicidad puede ser unificada por un caso central de derecho. Examinemos los dos roles clave del "caso central" que Finnis identifica.

En primer lugar, Finnis comienza con la idea de que un método descriptivo-explicativo necesita estar consciente de las diferentes concepciones y autointerpretaciones de las personas cuyas conductas y disposiciones dan forma al concepto a ser investigado.

La comprensión completa de las acciones y las prácticas implica una comprensión del sentido y propósito de la acción o práctica. El agente que ejecuta la acción o el participante que participa en la práctica le otorga su sentido y propósito - o valor - a la acción o práctica. Por lo tanto, el teórico entiende el valor o el sentido y propósito atribuido solo mediante la comprensión de las autointerpretaciones de los participantes (Finnis, 2011, p. 13). Sin embargo, el teórico es confrontado por el problema de la variedad de las concepciones sobre el valor o el sentido y propósito de la práctica y la acción. El sentido y propósito de una práctica cambia de persona a persona y de sociedad a sociedad (Finnis, 2011, p. 15).

¿Cómo puede el teórico organizar estas autointerpretaciones diferentes y conflictivas? En las ciencias humanas, los teóricos recurren a la identifi-

7 Finnis afirma que hay una interacción e interdependencia entre evaluar con la intención de actuar razonablemente bien y describir. Lo expresa como sigue: "Existe una interdependencia mutua, aunque no del todo simétrica, entre el proyecto de describir los asuntos humanos mediante la teoría y el proyecto de evaluar las opciones humanas con una intención, al menos remotamente, de actuar razonablemente y bien. Las evaluaciones no se deducen de ninguna manera de las descripciones, pero es muy poco probable que alguien cuyo conocimiento de los hechos de la situación humana sea muy limitado pueda juzgar bien en el discernimiento de las implicaciones prácticas de los valores básicos. Igualmente, las descripciones no se deducen de las evaluaciones, pero sin las evaluaciones nadie puede determinar cuáles descripciones son realmente esclarecedores y significativas" (2011, p. 19). 
cación de un factor común que unificará la variedad de las concepciones sobre el sentido y propósito - o valor- de una práctica y una acción. Esta estrategia es criticada por Finnis y ahora pasamos a tratar este punto.

El rol unificador constituye el segundo rol identificado por la metodología del "caso central". Encontrar una respuesta a la multiplicidad de concepciones y autointerpretaciones acerca del sentido y propósito de las acciones y de las prácticas significa buscar un factor común que cubra todas esas diferentes autointerpretaciones y concepciones. ${ }^{8}$ Kelsen, según Finnis, es consciente de que el sentido y propósito o función de una actividad es fundamental para el éxito de la tarea descriptivo-explicativa del contenido. Kelsen, nos dice Finnis, propone la idea de que el teórico necesita encontrar una cosa en común o el rasgo distintivo que caracteriza y explica el contenido (Finnis, 2011, p. 6). Esta idea presupone que el concepto de "derecho" está conectado a un solo rasgo distintivo.

Raz y Hart, nos dice Finnis, quiebran la metodología "ingenua" de Austin y Kelsen y alega que Austin y Kelsen se equivocan en lo que respecta a la función que se atribuye al derecho. Hart explica el concepto de derecho apelando al sentido práctico de los componentes del concepto. Tanto Raz como Hart hacen énfasis en que el derecho provee razones para la acción y busca guiar la conducta de los participantes jurídicos. También creen, según Finnis, en la idea de que esas diferentes concepciones tienen un principio o razón que las unifica (2011, p. 10).

Finnis critica a Kelsen porque presupone que hay un factor común a todas las diferentes concepciones del derecho. Pero también critica a Raz y a Hart, aunque ellos abandonan la idea de que hay una cosa en común a todos los casos del concepto de derecho, adoptan un "punto de vista práctico" inestable o insatisfactorio (Finnis, 2011, p. 13). Finnis utiliza el término "punto de vista práctico" para referirse a un punto de vista que

8 Hay una motivación paralela en la introducción de Aristóteles de la idea del "significado focal". Aristóteles quiere mostrar, contra Platón, que los conceptos de "ser", "bondad" o "amistad" no representan una sola esencia, sino diferentes esencias y propiedades. Sin embargo, pueden unificarse y por lo tanto pueden ser el sujeto de investigación de una disciplina, esto es, la metafísica en el caso del concepto de "ser". Véase Irwin (1981, p. 540). 
Rastreando las críticas de Finnis al punto de vista interno de Hart: inestabilidad...

aborda la decisión y la acción (2011, p. 12). Así Raz adopta "el punto de vista del hombre ordinario" y en una obra posterior Raz se refiere al "punto de vista jurídico" (1999), mientras Hart adopta el "punto de vista interno", es decir, el punto de vista del hombre que usa las reglas como un estándar para evaluar sus propias acciones y las de los demás. Los puntos de vista prácticos de Raz y Hart, nos dice Finnis, representan ir varios pasos más adelante que Austin y Kelsen, quienes presuponen al hombre que meramente acata el derecho a causa del miedo al castigo.

No obstante, Finnis encuentra inestables e insatisfactorios tanto el punto de vista interno de Raz como el de Hart, puesto que no pueden explicar la distinción entre diferentes puntos de vista, tales como aquel entre el anarquista y la ciudadana respetuosa del derecho. Los teóricos necesitan un principio o razón que les permita discriminar entre puntos de vista e identificar lo que es significativo o relevante cuando organizan las diferentes autointerpretaciones y concepciones del derecho.

En la literatura actual, la crítica de Finnis a la metodología de Hart y Raz ha encendido discusiones sobre las diferencias entre los casos centrales o focales ${ }^{10}$ y los casos defectuosos de derecho. ${ }^{11}$ La crítica de Finnis del punto de vista interno de Hart se centra en su carácter problemático para unificar las diferentes autoconcepciones y autointerpretaciones del derecho. Sin embargo, otra explicación del carácter problemático del punto interno de Hart puede encontrarse en la siguiente cita:

Pero todo esto es inestable e insatisfactorio porque involucra una negativa a atribuir relevancia a las diferencias que cualquier actor en el campo (bien sea el anarquista subversivo o su oponente, el "ciudadano respetuoso del derecho") consideraría como relevantes para la práctica (Finnis, 2011, p. 13).

9 Véase, para una discusión sobre las diferencias entre las metodologías de Raz y Finnis, Dickson (2001).

${ }^{10}$ Véase, para una visión alternativa sobre el caso central o el significado focal, Rodríguez-Blanco (2007).

${ }^{11}$ Murphy (2006) desarrolla una defensa de la metodología de Finnis. Por el contrario, Julie Dickson (2011) propone una distinción entre evaluación directa e indirecta y sostiene que la metodología de Finnis es cercana a la primera. 
En otras palabras, Finnis nos dice que el participante de la práctica jurídica, por ejemplo, la ciudadana, la jueza, la abogada, están comprometidas con el derecho y están interesadas en distinguir entre una norma buena y una no tan buena, entre una directiva justa y una directiva injusta, entre una decisión racional de un tribunal y una decisión irracional. El punto de vista interno de Hart se niega a hacer ulteriores distinciones entre los casos centrales y periféricos del derecho y esto trae inestabilidad al concepto.

El punto de vista interno de Hart como inestable puede remontarse a una crítica más fundamental, a saber, el punto de vista interno de Hart no puede ser usado para entender el sentido y propósito de las acciones humanas y, por lo tanto, no podemos basarnos en el punto de vista interno de Hart para identificar diferencias de importancia que pueda hacer cualquier actor en el campo. En la literatura sobre la "metodología", este argumento de la inestabilidad es pasado por alto y sus premisas no han sido cuidadosamente examinadas. En este capítulo, trataré de mostrar que la idea de que el punto de vista interno es inestable es, a la vez, clave para entender los límites de la teoría del derecho de Hart y para arrojar más luz sobre la idea de que el derecho debe concebirse en términos de un caso central o focal.

Podríamos inferir que, para Finnis, poner la razón práctica en el corazón del concepto de derecho provee el soporte que da estabilidad al concepto de derecho y nos permite aprehenderlo correctamente. Pero, ¿̨por qué la razón práctica constituye el caso paradigmático o "central" del derecho? ¿Por qué debería tener prioridad sobre otros puntos de vista internos, como por ejemplo el punto de vista del hombre o mujer malos o el punto de vista del anarquista? Además, ¿por qué provee estabilidad? ¿De qué tipo de estabilidad está hablando Finnis? Finnis (2003; 1998), Grisez (1967) y Tollefsen (2018) han defendido la prioridad del punto de vista de la razón práctica utilizando la concepción de Tomás de Aquino de la acción intencional y los cuatro órdenes de la naturaleza. No obstante, el teórico escéptico, el teórico del derecho crítico o la mala mujer de Holmes permanecen indiferentes a esta defensa y los argumentos de Finnis, Grisez o Tollefsen no los persuaden. A su vez, no parecen entender el veredicto de inestabilidad propuesto por Finnis contra el punto de vista interno de Hart.

Explicaré por qué surge esta inestabilidad, aunque no me basaré exclusivamente en la noción de acción intencional - la cual he defendido en 
Rastreando las críticas de Finnis al punto de vista interno de Hart: inestabilidad...

otra parte-, abogada por Aristóteles, Tomás de Aquino, Anscombe, Grisez, Finnis y Tollefsen, y los cuatro órdenes de la naturaleza. Mi estrategia argumentativa clave es negativa, a saber, mostrar que el modelo de la acción de Hart no puede dar cuenta del sentido y propósito (point) de las acciones humanas en el derecho.

Defenderé tres afirmaciones:

a) Entender una acción humana en el derecho supone comprender qué busca alcanzar dicha acción, esto es, su sentido y propósito.

b) El punto de vista interno de Hart no puede usarse para entender el sentido y propósito o los sentidos y propósitos de la acción. Su posición solamente muestra cuál puede ser el estado mental, esto es, la creencia, del agente que realiza una acción cuando sigue la regla del reconocimiento y/o las normas jurídicas en general.

c) Entender el estado mental interno de la acción no es comprender el sentido y propósito de la acción. Entender el estado mental del agente puede o no proveer de una comprensión del sentido y propósito de la acción, pero si lo hace puede considerarse mera casualidad. Por lo tanto, el punto de vista interno de Hart es inestable.

Presupondré que a) no es controversial, ya que el "sentido y propósito" de una acción puede construirse tan ampliamente como para incluir motivos, intereses y valores. En orden a mostrar que los estados mentales, esto es, las creencias, no pueden aprehender el sentido y propósito de una acción y su eventual contenido (b), utilizaré una teoría de la acción intencional defendida por Anscombe. Argumentaré que cuando observamos una acción desde la perspectiva de la tercera persona no aprehendemos el estado mental de quien la realiza, ni se nos provee de una interpretación de los movimientos corporales que constituyen las características distintivas físicas de la acción. Estamos tratando de "ver el sentido y propósito" de la acción para darle significado. Si no podemos ver el sentido y propósito o los sentidos y propósitos de la acción, es porque no estamos ejerciendo ciertas capacida$\operatorname{des}^{12}$ y disposiciones, a saber, la razón práctica y la imaginación práctica,

12 Entiendo capacidades como las habilidades de los seres humanos para realizar diferentes operaciones. En Aristóteles y Tomás de Aquino, la capacidad es entendida como la actua- 
y estas capacidades se aprenden mediante juegos de lenguaje insertos en las formas humanas de vida.

Podría decirse que somos ciegos para ciertos aspectos del sentido y propósito de una acción. Es tentador reemplazar teóricamente esta ceguera con una teoría de los estados mentales; por ejemplo, la creencia de que una acción corresponde al tipo de acción que es jurídica, u otras ficciones que oscurecen la comprensión de las acciones humanas. Finalmente, sostendré que la inestabilidad se produce porque necesitamos contar con rememorar nuestros estados mentales y podríamos no ser capaces de recordar nuestras creencias sobre las normas jurídicas. Podría recordar mi estado mental de creencia en la regla de reconocimiento o en las normas jurídicas en general, pero esto es mera casualidad. No hay ruta que garantice que recuerde y aprehenda el significado o sentido y propósito de una acción. Por el contrario, en orden a "ver el sentido y propósito de una acción", por el cual se ejercen ciertas capacidades y disposiciones, necesitamos ejercer la capacidad de reconocer las acciones aprendidas en los juegos del lenguaje. No debemos oscurecer el "sentido y propósito de la acción" con ficciones como los estados mentales, puesto que al hacerlo perdemos al agente y a la acción misma.

El ensayo se divide en dos partes: en la primera parte utilizo la teoría de Anscombe de la acción intencional para arrojar luz sobre "ver el sentido y propósito de una acción humana" y trato el tema del aprendizaje del logos de la práctica social como el ejercicio de nuestras capacidades dentro de formas de vida específicas. En la segunda parte, profundizo más en la crítica de Finnis a la inestabilidad del punto de vista interno y defiendo la afirmación de Finnis de que el ejercicio de nuestra capacidad para la razón práctica es el caso central de la acción humana y por tanto de la acción humana en el derecho.

lidad de una potencialidad. Una capacidad clave es la habilidad de los seres humanos para actuar en el mundo y producir cosas, valores, situaciones. Esto incluiría también las disposiciones, ya que las capacidades aprendidas son disposiciones (Aquinas, 2006c). Una discusión completa de las capacidades y las disposiciones va más allá del argumento central de este ensayo. Véase, para una discusión de las capacidades como actualización de potencialidades, con un enfoque especial en el razonamiento práctico, Rodríguez-Blanco (2016a, capítulo 4). 
Rastreando las críticas de Finnis al punto de vista interno de Hart: inestabilidad...

\section{2. "Ver el sentido y propósito de una acción" y una teoría de la acción intencional}

Nuestras acciones no son meros movimientos físicos o las representaciones de uno o más estados mentales, nuestras acciones tienen una dimensión interna que les confiere unidad. Más precisamente, esta unidad resulta de la elección y la decisión del agente.

La elección que se expresa a sí misma en el ámbito físico en ciertos movimientos los convierte en un cierto tipo de acción o constituye su naturaleza o especie. ${ }^{13} \mathrm{Al}$ ser esto así, nos incumbe preguntar cómo esta dimensión interna puede ser inteligible a terceras personas. Por ejemplo, cuando veo a alguien sentado ante un escritorio que traza líneas sobre una hoja de papel con ciertas características, puedo entender que está escribiendo una carta si y solo si yo aprehendo lo que intenta hacer. Esta dimensión interna es inteligible porque el logos de las acciones intencionales - en otras palabras, las razones detrás de las acciones- pueden ser entendidas mediante el contexto específico de la ejecución externa. Comprendo las intenciones de quien escribe la carta, por ejemplo, porque reconozco los objetos con las características típicas de la papelería y los sobres sobre su escritorio y sé lo que se requiere para la práctica de escribir cartas.

Anscombe discute esta relación entre la ejecución exterior de las acciones y los hechos o contextos institucionales en los cuales estas ocurren en su artículo de 1958 titulado "Sobre los hechos brutos". En lo que mi coautora y yo hemos llamado su tesis de la transparencia institucional, Anscombe sostiene que mientras una descripción factual de una acción " $\mathrm{A}$ " no es una descripción de la institución detrás de " $A$ " (1958, p. 72), la existencia de una descripción factual de la acción "A" presupone una institución A. Puesto en el contexto de la inteligibilidad, entender la dimensión interna (esto es, la intención o la elección) de las acciones de una tercera persona requiere comprender el contexto social o institucional en el que dichas acciones ocurren. Para comprender que la emisión de ciertas palabras por parte de alguien es, por ejemplo, una promesa, necesito saber cómo están

${ }^{13}$ En lo que sigue, desarrollo un argumento que ya había esbozado Rodríguez-Blanco y Zambrano (2018). 
institucionalizadas las promesas en mi comunidad, aun cuando - y esta es la tesis de la transparencia- no necesite pensar sobre eso cuando yo prometo o cuando reconozco una promesa. Además, la inteligibilidad de esas acciones acontece no en el ámbito teórico, sino en el de lo práctico.

Para explicarlo mejor, tenemos que preguntar cuál es la institución detrás de la descripción. Anscombe ofrece un ejemplo que podemos usar como punto de partida: "Debo al tendero cinco libras de papas que me suministró".

Digamos que ordené cinco kilogramos de papas al tendero; el tendero carga las papas en su camioneta de reparto; conduce hasta mi casa; toca el timbre; descarga las papas de su camioneta y me da una factura por cinco libras. Usted observa tanto mis acciones como las del tendero. Concluye, como un observador, que "debo al tendero cinco libras". Usted llega a esa conclusión. Pero, ¿cómo? ¿Llega a esa conclusión porque me pregunta qué estoy haciendo y yo se lo digo? Pero usted solamente haría esta pregunta si lo que estoy haciendo es ininteligible para usted. Usted comprende tanto la manera en que muevo mi cuerpo como las razones por las cuales muevo mi cuerpo como una unidad. A menos que usted ya posea los conceptos necesarios para comprender las razones por las cuales yo muevo mi cuerpo -conceptos tales como suministrar, deber y cinco libras-, simplemente observar la manera en que el tendero y yo movemos nuestros cuerpos cuando recibo las papas y la factura por cinco libras no le dirá a usted que "yo debo al tendero cinco libras por las papas que me ha suministrado". La obligación de deber solo le resulta inteligible si usted ya comprende de antemano la acción de suministrar como la razón para la obligación de deber. En ese caso, ya usted ha aprehendido conceptos tales como suministrar, deber y cinco libras antes de los movimientos corporales entre el tendero y yo. Usted, yo y el tendero hemos aprendido previamente dicho conjunto de conceptos dentro del contexto de la institución social de comprar y vender. Hemos aprendido el conjunto de conceptos cuando éramos jóvenes y aprendimos que el intercambio de bienes en nuestra sociedad crea obligaciones. Aprendimos como una unidad los movimientos corporales y las razones por las cuales compramos, vendemos y satisfacemos nuestras obligaciones en el intercambio de bienes. Mis movimientos corporales, los movimientos corporales del tendero y las razones por las cuales ejecu- 
Rastreando las críticas de Finnis al punto de vista interno de Hart: inestabilidad...

tamos dichas acciones - en otras palabras, el logos de esas acciones-, son comprendidos como un todo en el ejemplo de Anscombe. Su comprensión, como un observador, de la unidad de los movimientos corporales y de las razones por las cuales se ejecutan esos movimientos corporales no describe la institución de comprar y vender. Más bien, esta institución de fondo le provee de las bases por las cuales usted puede determinar las intenciones detrás de los movimientos corporales que imprimen un logos sobre esos movimientos corporales.

Como la acción es práctica, debería ser entendida como práctica. Podemos decir que la acción es "práctica" porque en ella se trata de las intenciones del tendero y del comprador. El tendero y el comprador tienen la intención de producir un cierto estado de cosas y saben por qué hacen lo que están haciendo. El tendero sabe por qué carga cinco kilogramos de papas en su camioneta de reparto, conduce hasta mi casa, toca el timbre y descarga las papas enfrente de mi casa. Como comprador, sé por qué estoy ordenando papas, por qué las recibo del tendero y por qué recibo la factura por cinco libras. Adicionalmente, ambos sabemos qué está haciendo el otro y por qué lo están haciendo, porque ambos entendemos la institución de fondo de comprar y vender que nos permite hacer inteligibles nuestros movimientos.

Anscombe pregunta si los mismos movimientos corporales en un film donde un actor entrega las papas y otro actor recibe las papas serían diferentes de los del ejemplo anterior. En dicho ejemplo, como comprador, yo debo al tendero cinco libras, mientras que en el film no diríamos que el actor que interpreta al comprador le debe cinco libras al actor que interpreta al tendero, porque la intención de los agentes es diferente. A pesar de los movimientos de los actores en el film, estos no intentan crear un contrato de compra o la obligación de satisfacer un contrato semejante. Cuando el tendero me extiende la factura en el ejemplo, yo soy el comprador y el tendero y yo tenemos la intención de crear tal contrato. Por lo tanto, yo entiendo que debo al tendero cinco libras. Y el observador, que comprende la diferencia entre las instituciones de fondo en cada situación, comprende la diferencia entre esas dos situaciones.

Para comprender mejor este sutil y difícil punto necesitamos entender la concepción de Anscombe de la acción intencional, que rechaza las 
acciones como una cadena causa-efecto de dos eslabones compuesta de un acto interior - esto es, los estados mentales tales como las creencias y los deseos que causan una acción-, y la acción exterior que es el efecto del acto interior. Como Tomás de Aquino, Anscombe no separa la acción física y la respuesta a la pregunta acerca de por qué el agente está actuando de la manera en que lo hace. Si la pregunta por qué no puede aplicarse a la acción física, entonces es más que probable que la acción no haya sido intencional. Lo cual es decir que no hay dos acciones, una interior y una exterior, sino una sola acción. Diferentes perspectivas pueden analizar esa acción, pero la acción exterior es una y la misma y no esencialmente diferente de la voluntad interior. La única acción es su ejecución y manifestación (Aquinas, 2006a, q. 17, a. 4).

¿Qué es, entonces, la elección o voluntad que se ejecuta y manifiesta por medio de la acción exterior? Para responder, debemos determinar si existe o no una distinción entre la intención de actuar - en cuyo caso mi voluntad es operante y está envuelta en la acción-, y una acción voluntaria. Por supuesto que las acciones pueden ser voluntarias: por ejemplo, hablar, caminar, saltar, etc. son acciones voluntarias. Las acciones también pueden ser involuntarias: por ejemplo, las funciones respiratorias de mi cuerpo y de mi sistema digestivo son acciones involuntarias. Pero, para las acciones voluntarias específicamente, ¿involucran todas las acciones voluntarias la voluntad? Puesto más concretamente, ¿involucran todas las acciones voluntarias una elección? (Aquinas, 2006a, q. 17, a. 4).

Consideremos dos ejemplos diferentes. En uno, muevo mi brazo, pero en lugar de moverse mi brazo, se mueven mis pies. En otro, muevo mi brazo y mi brazo, en efecto, se mueve. Mis acciones son voluntarias en ambos ejemplos. Sin embargo, en el primer ejemplo, mi acción no ejecuta mi elección. Mi elección es mover mi brazo, y en este primer ejemplo, mi elección no se cumple. Si me estuviera observando en esos dos casos, notaría que mi pie se mueve y después vería a mi brazo moverse. ¿Cómo sería usted capaz de determinar si se cumplió efectivamente mi elección en cada caso? Podemos hacer una distinción, entonces, entre un acto meramente volitivo, esto es, un acto iniciado por una persona, y un acto voluntario, esto es, un acto volitivo que efectivamente lleva a cabo una elección. Dicho esto, ¿ cómo puede un observador conocer si el acto es volitivo o volunta- 
Rastreando las críticas de Finnis al punto de vista interno de Hart: inestabilidad...

rio? Los observadores podrían ver que muevo mi pie y mi brazo, pero no pueden conocer mi elección, de tal forma que no pueden saber, tan solo a partir de la observación, que mi brazo se movió intencionalmente.

Podría decirse que la vía para determinar si una acción es o no querida es pedir al agente que describa la acción. Por ejemplo, podemos ver a Juan mover su mano y golpear a Marcos y preguntarle a Juan si su movimiento - que fue claramente volitivo-, pretendía golpear a Marcos o si el golpe fue accidental. Pero, aun cuando la descripción del agente es la mejor manera para determinar si la acción es querida o no, solo raramente se les pide a los agentes que describan sus acciones porque, en la mayoría de los casos, el trasfondo institucional o los juegos del lenguaje, en combinación con los movimientos físicos de la acción son suficientes para efectuar tal determinación. Si Juan golpea a Marcos mientras están en un cuadrilátero vestidos con shorts y guantes de boxeo, sabemos que el golpe fue intencional. La descripción del agente de sus elecciones puede incluso volverse irrelevante, como en el contexto del derecho, donde el trasfondo institucional hace inteligibles esas elecciones.

Ocuparse teóricamente de la acción humana está más cerca de una explicación que de una forma de comprensión. En el conocimiento teórico o metafísico, las acciones se individualizan a través de un proceso cognitivo que se focaliza no en identificar elecciones que se ejecutan en acciones, sino en identificar las acciones como efectos de eventos previos. Donald Davidson (1963), en sus consideraciones sobre la acción intencional, defiende su teoría causal de la acción y la teoría correlativa de la interpretación de las acciones concretas.

Muchos estudiosos han asumido que Davidson y Anscombe sostienen visiones similares sobre la acción intencional, porque Davidson usa algunas de las ideas de Anscombe y a causa de la dificultad y complejidad de la obra de Anscombe, que no se basa en una teoría general o un sistema (Annas, 1976). No obstante, las consideraciones de Anscombe y Davidson sobre la acción intencional y sobre la interpretación de la acción son, de hecho, fundamentalmente diferentes.

Para Davidson, las acciones intencionales son comprendidas en términos de las razones que el agente da cuando describe lo que hizo. El objetivo es racionalizar la acción. Además, se puede decir que el agente tiene una 
razón si a) el agente es proactivo hacia la acción y b) el agente cree (o sabe, recuerda, nota, percibe) que su acción es de ese tipo (Davidson, 1963, p. 685). Davidson denomina a esta combinación de creencia y deseo una razón primaria y sostiene que "una razón primaria para una acción es su causa" (Davidson, 1963, p. 685).

En las consideraciones de Davidson, las creencias y los deseos son meros eventos mentales que causan (o pueden eventualmente hacerlo) una acción externa, que es un evento subsecuente y correspondiente. La relación entre eventos mentales y acciones es causal, específicamente un tipo de relación causal entre hechos (Davidson, 1963, p. 685). Así, mi deseo de accionar un interruptor y mi creencia de que mi acción es de ese tipo causa la acción yo acciono el interruptor. Además, la observación de la acción nos permite inducir la causa. Aun cuando solo observemos el efecto, esto es, la acción, la cual en este caso es el movimiento del interruptor, podemos inducir la causa, esto es, los eventos mentales que causaron el efecto. Este proceso cognitivo que nos permite individuar la naturaleza de varias acciones no es fundamentalmente diferente del proceso cognitivo que explica los eventos físicos.

Davidson niega que haya leyes psicofísicas que conecten las acciones y las razones, al decir que si hay leyes, estas deberían ser neurológicas, químicas o físicas (Davidson, 1963, p. 685). En los últimos cuarenta años, sus consideraciones sobre la acción intencional han ejercido gran influencia. En ese tiempo, el razonamiento práctico ha tendido a ser asimilado dentro de la acción intencional como un estado mental. ${ }^{14} \mathrm{La}$ asimilación del razonamiento práctico a un estado mental ofrece dos ventajas sobre consideraciones rivales como la de Anscombe. Una, esta asimilación permite a los neo-humeanos ${ }^{15}$ plantear la idea de Hume de que los deseos o actitudes proactivas motivan y explican las acciones intencionales. Dos, esta asimilación es compatible con una comprensión descriptiva y científicamente neutral de la acción como causada por eventos mentales. A pesar de estas

${ }^{14}$ Ver, por ejemplo, Wallace, (s. f.): "El razonamiento práctico da lugar no a movimientos corporales per se, sino a acciones intencionales, y estas son inteligibles como tales solo en la medida en que reflejen nuestros estados mentales".

15 Véase, para versiones de esta tesis, Harman (1986a; 1986b); Blackburn (1998); Smith (1994). 
Rastreando las críticas de Finnis al punto de vista interno de Hart: inestabilidad...

ventajas, la visión de Davidson contiene un defecto notable, a saber, que no tiene manera de garantizar que el vínculo causal entre una razón y la correspondiente acción sea correcto. ${ }^{16}$

Hay otros problemas que afectan el modelo estándar de la acción intencional. Si una intención de actuar es un estado mental, esto implica que puedo recordar mi estado mental y reflexionar sobre él. Desafortunadamente, parece que la memoria o la habilidad para reflexionar sobre mi intención como un estado mental pueden desvanecerse. Si las intenciones son puramente estados mentales que pueden desvanecerse, podríamos no recordarlas correctamente, podrían no perdurar, y entonces también podría desvanecerse nuestra acción intencional.

En conclusión, poner las acciones humanas en el mismo nivel como eventos físicos/teóricos o metafísicos, o poner la comprensión de las acciones humanas en el mismo nivel como la explicación de relaciones causales efectivas, falla en garantizar la individuación de las acciones.

Como fue previamente discutido, la mejor manera para determinar si un agente quiso una acción, es solicitar al agente mismo una descripción de la acción. Podemos solicitar una descripción de la acción preguntándole al agente por qué ejecutó una acción (Anscombe, 1963). Solicitar una descripción de esta manera se conoce como la metodología de la pregunta del porqué y es el método clave en Intención de Anscombe para clarificar las conexiones entre nuestras acciones y nuestro razonamiento práctico. ${ }^{17}$ Comprender plenamente esta metodología requiere dar cuenta de varias consideraciones:

a) Paradigmáticamente, una acción intencional es una secuencia de acciones orientadas hacia el fin último de la acción.

b) Sabemos que la explicación finaliza porque el último paso es descrito en los términos de características beneficiosas que hacen inteligibles e iluminan como un todo coherente los pasos sucesivos de la acción.

${ }^{16}$ Chisholm fue el primer estudioso que escribió sobre cadenas causales desviadas (1976, p. 28). Otros estudiosos más radicales van más allá y niegan que las acciones intencionales sean causas. Véase, por ejemplo, Dancy (2000).

17 La exposición de Anscombe sigue muy de cerca la explicación de Tomás de Aquino de la acción intencional. Notablemente, Kenny (1979) argumenta que el modelo de Tomás de Aquino se entendería mejor como una psicología Gestalt. 
c) Tenemos solamente una acción, no diferentes acciones, y esa única acción se unifica en virtud del fin último de la acción, como una razón para la acción, entendida con respecto a las características beneficiosas.

d) La razón tiene que ser una razón que pudiera ser genuinamente ofrecida a los otros como una justificación, y esta razón tiene que ser también la misma que el agente se da a sí mismo.

Con esas consideraciones en mente, podemos explicar ahora la metodología de la pregunta del porqué.

Anscombe comienza Intención planteando que el tema del libro debe ser estudiado bajo tres títulos: expresión de una intención; acción intencional e intención en el actuar, ${ }^{18}$ y que todos ellos deben entenderse como interdependientes. Así, una expresión de una intención no puede entenderse como una predicción sobre mis actos futuros ni como una explicación introspectiva de una intención tal como los deseos, necesidades, etc. Si yo digo "esta tarde iré a caminar" como una expresión de una intención, esas palabras no pueden entenderse como un pronóstico del futuro. En efecto, la intención está correctamente expresada en las palabras que fueron emitidas, aun cuando resulte que habrían sido falsas en tanto que pronóstico, ya que un amigo viene a visitarme y no puedo salir de casa. Ni pueden las palabras emitidas ser una expresión de deseos o necesidades. Yo podría tener la intención de caminar aun cuando yo no tenga ningún deseo en absoluto de hacerlo: por ejemplo, podría necesitar caminar hasta la casa de un amigo a devolver un libro, incluso si yo haría más bien otra cosa. Anscombe nos dice, sin embargo, que las personas formulan expresiones de intenciones sobre el futuro y usualmente resultan ser correctas (Anscombe, 1963, pp. 3-4). ¿Cómo es esto posible?

Para responder esta pregunta ella trata de explicar la manera en la cual podemos identificar los actos intencionales y separarlos de los actos no-intencionales. Hacer esto requiere dar el paso lógico de tratar de entender qué significa que yo diga "he actuado con una intención". Para Anscombe,

${ }^{18}$ Moran y Stone explican la transformación de esos tres títulos en la literatura posterior a Intención (2009, p. 37). 
Rastreando las críticas de Finnis al punto de vista interno de Hart: inestabilidad...

actuar intencionalmente significa actuar por una razón o ser capaz de dar razones para la acción, en el entendido de que pueda decirse que la pregunta por qué aplica a tales acciones (Anscombe, 1963, pp. 4-6). Todo lo cual es decir que actuamos intencionalmente cuando actuamos por razones, lo que a su vez nos obliga a ser receptivos y sensibles a un marco de justificación para nuestras acciones. Si ejecuto una acción $\Phi$, se me pregunta por qué he ejecutado $\Phi$ y doy una respuesta genuina, por ejemplo, "no estaba consciente de que estaba haciendo $\Phi$ " o "no sabía que estaba ejecutando $\Phi$ ", no puede decirse que la acción sea intencional o dirigida por razones. La acción puede ser voluntaria, pero no es intencional (Anscombe, 1963, p. 17). Por el otro lado, si la respuesta tiene una de estas formas: "porque $\Phi$ " o “en orden a $\Phi$ ”, entonces podría ser prima facie un caso para una acción intencional, lo que es decir una acción dirigida por razones. Las razones se demuestran ellas mismas, por así decirlo, en las acciones intencionales y las razones demuestran que operan como una parte del razonamiento práctico de un agente.

El problema para la comprensión de la acción es si estamos o no en control de la veracidad de las intenciones cuando se nos pregunta por qué hemos ejecutado una acción. Otro problema adicional se presenta por sí mismo: si podemos o no dar una respuesta plausible sin depender del testimonio del agente de la acción.

Anscombe nota que un conjunto de condiciones contextuales nos permite determinar si el agente ha dado o no sus genuinas intenciones como respuesta la pregunta por qué (Anscombe, 1963, p. 25). Este conjunto de condiciones contextuales son aquellos conceptos aprendidos en edad temprana mediante el contexto social. Por ejemplo, aprendemos que el dinero es necesario para comprar bienes y que si ordenamos bienes para la entrega a domicilio deberemos dinero al vendedor. En nuestro ejemplo de una escena de un film en la cual un tendero entrega papas, sabemos, a partir de las condiciones contextuales, que cuando el actor-comprador dice que le debe al actor-tendero cinco libras, las palabras del actor-comprador no son genuinas. O dado el ejemplo que muestra Anscombe en Intención, si una persona envenena un río con desechos tóxicos, preguntamos “ ¿por qué?" y la persona responde "solo estoy haciendo mi trabajo", podremos determinar si la acción es parte de su trabajo o no y si las condiciones 
contextuales lo hacen verdadero o no y, si no, entonces tenemos una razón para sospechar que su respuesta no es genuina.

Las acciones intencionales, o las acciones ejecutadas por razones, requieren una secuencia de pasos o acciones y, por lo tanto, una secuencia de razones que expliquen cada acción-paso. Si alguien escribe una carta y tiene una razón para hacerlo (por ejemplo, saludar a un amigo), lo hace así tomando una hoja de papel y una pluma y trazando letras con la pluma sobre el papel. Escribir la carta es su razón para trazar líneas sobre la hoja y esto último es su razón para tomar la hoja de la gaveta. Si este es el caso, surge la pregunta acerca de cómo podemos saber cuándo la explicación es completa y el agente puede dejar de dar justificaciones. Anscombe argumenta que la justificación se detiene cuando el agente describe el sentido y propósito final de la acción, en relación con lo que es deseable o bueno por sí mismo. El sentido y propósito final de la acción es, entonces, un estado de cosas, un hecho, un objeto o un evento que el agente parece considerar deseable o bueno. El estado de cosas, hecho, objeto o evento es considerado por el agente como algo bueno. Esta explicación es de sentido común y se podría decir que es la explicación más ingenua de nuestras acciones. ${ }^{19}$ Por ejemplo, cuando las papas han sido entregadas en mi casa, el tendero no dice que las ha entregado porque está en el estado mental de desear entregar papas y tiene el estado mental de creer y recordar que este es dicho tipo de acción. Por el contrario, para suministrar las papas, el tendero carga las papas en su camioneta de reparto, maneja hasta mi casa, la estaciona enfrente de mi casa, sale de la camioneta, descarga las papas, toca el timbre de mi puerta y lleva las papas hasta mi cocina. La secuencia de los pasos de la acción cobra inteligibilidad y unidad en la razón beneficiosa de que, por ejemplo, el tendero vende papas que compra a los granjeros, que quiere ganar dinero, etc.

Recordemos la diferencia con los actores en la escena de film comprando y vendiendo papas. Desde el punto de vista de los agentes, su intención de adquirir un bien específico era lo que diferenciaba las acciones de los actores en el film de las acciones del tendero que entrega papas en mi casa. En la escena del film comprando y vendiendo papas, los actores 
Rastreando las críticas de Finnis al punto de vista interno de Hart: inestabilidad...

no buscan comprar y vender papas, por lo que no podemos decir que el actor-comprador le debe cinco libras al actor-tendero.

Para retornar a nuestra discusión inicial, ¿cómo puede la intención/ elección del agente hacerse inteligible para un observador y permitir al observador individualizar dicha intención/elección? Inteligibilidad requiere $i$ ) que tanto el agente como el observador sostengan un entendimiento mutuo de cuáles características beneficiosas pueden ser buscadas o escogidas por el agente cuando ejecuta una acción, y ii) que las características beneficiosas buscadas por el agente se manifiesten en la acción. La primera condición requiere que las características beneficiosas no existan puramente a través de la convención, ni que sean reconocibles a través de métodos empíricos, sino que sean, al menos hasta cierto punto, los objetos de la inteligencia humana. Si las características beneficiosas no fueran objetos de la inteligencia humana, el agente no sería ni siquiera capaz de nombrarlas. La segunda condición requiere que las características beneficiosas que se pretenden de una acción sean un caso específico de las características beneficiosas del trasfondo institucional o prácticas sociales que le dan a las acciones su forma final o logos (Grisez, 1967, p. 174). ${ }^{20}$

Con estas condiciones en mente, el objetivo primario de la metodología de la pregunta del porqué es destacar la articulación o estructura de una acción intencional (Vogler, 2001). En nuestro ejemplo de las papas, el tendero no piensa y reflexiona sobre por qué está haciendo lo que hace a cada paso concreto de la acción. Más bien, el tendero entiende la secuencia de los pasos de la acción necesarios para comprar y vender y las características beneficiosas que explican por qué nosotros, los seres humanos, compramos y vendemos en el contexto social.

El asunto, entonces, no es descubrir las actitudes proposicionales - los deseos y las creencias que explican el vender y el comprar-, ni siquiera describir explícitamente la institución de comprar y vender, ni descubrir la naturaleza de la acción humana en términos de un bien dado. El asunto es comprender si la acción es o no intencional y entender qué elección pretende el agente cuando ejecuta la acción. Poniendo el testimonio del agente de lado por el momento, solo es posible entender la elección del

20 Véase, para un desarrollo más amplio de estos argumentos, Zambrano (2015). 
agente si su acción es comprendida como un caso específico dentro de una práctica social y justificada por las características beneficiosas de dicha práctica social. Solo cuando la comprensión de estos aspectos está en su lugar puede el observador aprehender la acción intencional como una unidad de movimientos físicos y la respuesta a la pregunta por qué, o el logos fundante de la acción.

\section{Rescatando el concepto de derecho: la defensa de Finnis de la razón práctica como el caso central}

Una vez que hemos mostrado la idea de que las acciones intencionales devienen inteligibles debido a la transparencia institucional y los juegos del lenguaje en los cuales están insertas, y la idea de un logos en la forma de valores y características beneficiosas que subyacen a las acciones intencionales - lo cual presupone el ejercicio de nuestra capacidad de razón práctica一, examinaremos ahora si esta concepción de la acción intencional arroja alguna luz sobre la crítica de Finnis del punto de vista interno de Hart.

Finnis apunta a establecer que el punto de vista interno de Hart es inestable y que un remedio para tal inestabilidad es el reconocimiento de que el caso central de derecho surge de personas que ejercitan sus capacidades de razonamiento práctico al comprometerse con el derecho. Pero hay un déficit de claridad sobre por qué hay inestabilidad y cómo nuestra capacidad de razonamiento práctico provee una solución adecuada a la inestabilidad diagnosticada.

Hart (1994, pp. 54-61) nos dice que cuando las personas ven las normas jurídicas desde su aspecto interno, hay una aceptación de tales reglas y esto implica que:

a) La conducta en cuestión es vista como un estándar general a ser seguido por el grupo.

b) Hay una actitud crítica entre las personas hacia este patrón de conducta. El estándar general aplica a todos los participantes en la práctica social y, en consecuencia, hay un amplio uso de las expresiones críticas en el lenguaje normativo, tales como "tú debes", "eso es correcto", etc. 
Rastreando las críticas de Finnis al punto de vista interno de Hart: inestabilidad...

Estas dos características clave nos capacitan para distinguir las normas jurídicas de los hábitos y de las órdenes respaldadas en amenazas. Es interesante que Hart también distinga entre la idea de reglas sociales en tanto que tienen un aspecto activo, esto es, la perspectiva interna, y un aspecto pasivo, esto es, órdenes respaldadas por amenazas. Esta explicación es digna de ser citada en su totalidad:

Es la fuerza de la doctrina que insiste en que la obediencia habitual a órdenes respaldadas por amenazas es el fundamento de un sistema jurídico la que nos obliga a pensar en términos realistas sobre este aspecto relativamente pasivo del complejo fenómeno que llamamos la existencia de un sistema jurídico. La debilidad de la doctrina es que oscurece o distorsiona el otro aspecto relativamente activo, el cual es visto primaria, aunque no exclusivamente, en las operaciones de creación, identificación y aplicación del derecho de los oficiales o expertos del sistema. Ambos aspectos deben mantenerse a la vista si vamos a ver este complejo fenómeno social por aquello que realmente es (Hart, 1994, p. 61, la cursiva me pertenece).

Desafortunadamente, el aspecto interno como mera aceptación de una crítica estándar y reflexiva no es suficiente para establecer la distinción activo/pasivo que Hart quiere mostrar tan vehementemente como se evidencia en el párrafo citado. ${ }^{21}$ Cuando aceptamos normas jurídicas y esas reglas son vistas como el estándar y cualquier desviación puede ser sujeto de crítica reflexiva, entonces hay solo una diferencia de grado y no en el tipo de nuestro compromiso con el derecho. De acuerdo con Hart, la acción del participante jurídico es captada por un observador a través del siguiente mecanismo: este reconoce un patrón de conducta externa que critica cualquier desviación del estándar que haya sido previamente aceptada por el participante. Si esto es así - me gustaría alegar-, es entonces una mera casualidad si el observador puede conectar el estado mental, esto es, los deseos y creencias del participante jurídico con el patrón de conducta

${ }^{21}$ Ver, para un intento de defender el elemento "activo" de la teoría legal de Hart, Gardner (2000). Para una crítica de esta posición, ver Rodríguez-Blanco (2018). 
observado del mismo. Este es el corazón de la así llamada inestabilidad del punto de vista interno de Hart. Me explico.

El estado mental de la creencia, esto es, de la aceptación de la norma jurídica, produce un patrón de conducta, pero no podemos tener la certeza de que este patrón particular de conducta esté siempre acompañado del estado de creencia correcto, a saber, entender el sentido y propósito de la acción del participante y comprometerse con la acción a causa de este sentido y propósito. En consecuencia, y como era de esperar, el anarquista y la mala mujer podrían tener un cierto patrón de conducta y tener la creencia de la aceptación porque pueden aceptar la norma jurídica por cualquier razón o motivo. No obstante, ni el anarquista ni la mala mujer verían ningún sentido y propósito valioso en las acciones que se comprometen con el derecho, ni podríamos nosotros hacer inteligible por qué ellos rechazan el derecho, a menos que entendamos que ellos han elegido hacerlo así. Pero una vez que introducimos la noción de "elección", necesitamos pensar acerca de una acción intencional que es guiada por un logos como lo son las características beneficiosas desde el punto de vista del agente. Por ejemplo: el anarquista da prioridad a su autonomía radical y a su libertad y esto dota a sus acciones contra el derecho de un sentido y propósito. Además, una vez que introducimos la "elección" y reflexionamos sobre la inteligibilidad de la elección, entonces la idea de un patrón de conducta se vuelve teóricamente innecesaria. No cumple ninguna función en tanto que todo el trabajo es hecho por nuestra comprensión de la acción intencional. Explicaré este punto más extensamente.

La idea de Hart de que aceptamos las normas jurídicas desde una perspectiva interna presupone una aproximación introspectiva a la acción como opuesta a una aproximación que mira hacia la exterioridad. Esta última examina las acciones intencionales como una serie de acciones que están justificadas en términos de otras acciones y en vista del propósito o finalidad de la acción intencional en tanto que una característica benéfica, por ejemplo, encender la tetera para hervir el agua, para hacer té porque es placentero beber té. Lo primero examina los estados mentales que racionalizan las acciones. Sin embargo, en el ámbito ontológico, se argumenta que esos estados mentales causan las acciones. Los estados mentales están compuestos por la creencia y la actitud proactiva hacia la acción. 
Rastreando las críticas de Finnis al punto de vista interno de Hart: inestabilidad...

Si la "tesis de la aceptación" es la interpretación correcta de la idea central de Hart concerniente al punto de vista interno hacia las normas jurídicas, las críticas que se levantan contra las aproximaciones introspectivas de las acciones intencionales también son válidas para el punto de vista interno de Hart y su "tesis de la aceptación". La crítica principal que se ha elevado contra la idea de que el par de creencia y actitud proactiva puede explicar las acciones intencionales es la visión de que este no puede explicar las desviaciones de la cadena causal ${ }^{22}$ entre los estados mentales y las acciones.

Supongamos que usted pretende matar a su enemigo arrollándolo con su vehículo esta tarde cuando se encuentre con él en su casa. Algunas horas antes de que usted intente matar a su enemigo, usted conduce hacia el supermercado, lo ve caminar sobre el pavimento y usted sufre un espasmo nervioso que causa que súbitamente gire el volante y atropelle a su enemigo. En este ejemplo, de acuerdo con la visión de la creencia y la actitud proactiva, hay una acción intencional si usted desea matar a su enemigo y usted cree que la acción de matar a su enemigo, bajo cierta descripción, tiene esa propiedad. Ontológicamente, la teoría establecería que usted tiene tanto el deseo de matar a su enemigo como la creencia de que esta acción tiene la propiedad "matar a su enemigo". Así, este estado mental ha causado la acción y hay una acción intencional. El problema con esta visión es que necesita especificar la ruta causal apropiada. Davidson ha hecho mucho esfuerzo en especificar las "actitudes que causan la acción si ellas van a racionalizar la acción":

Y aquí vemos que el análisis de Amstrong, como el que propuse pocas páginas atrás, debe hacer frente a la pregunta de cómo las creencias y los deseos causan las acciones intencionales. Las creencias y los deseos que racionalizarían una acción si la causan de la manera correcta - mediante una causa de razonamiento práctico, como podríamos intentar decir- pueden causarla de otras maneras. Si es así, la acción no fue ejecutada con la intención que podríamos haber leído a partir de las actitudes que la causaron. Lo que estoy desesperado por explicar en detalle es la manera en que las actitudes deben causar acciones si ellas van a racionalizar la acción (1980, p. 79).

22 La primera persona en discutir las cadenas causales desviadas fue Chisholm (1976). 
En el siguiente párrafo, Davidson parece temer que la idea de actitudes que causan acción pueda conducir a una regresión infinita:

Un escalador podría querer deslastrarse del peso y del peligro de sostener a otro hombre en la cuerda, y podría saber que al soltar la cuerda podría librarse del peso y del peligro. Esta creencia y este deseo podrían desconcertarlo tanto como para causar que soltase la cuerda, y sin embargo podría ser el caso que él nunca eligió soltarla, ni lo hizo intencionalmente. No ayudará, pienso, añadir que la creencia y el deseo deben combinarse para causar que él quiera soltar la cuerda, porque permanecerán las dos preguntas de cómo la creencia y el deseo causaron el segundo deseo y de cómo querer soltar la cuerda causó que la soltara (1980, p. 79).

Aquí vemos a Davidson luchando con su propia propuesta. ${ }^{23}$ Pregunta cómo las actitudes deben causar acciones si ellas están para racionalizar las acciones. El modelo de Davidson de la acción intencional no nos ayuda a determinar si existe una acción intencional, solo nos ayuda a determinar las condiciones que explicarían la existencia de una acción intencional. La acción intencional ya está dada. Una crítica similar es aplicable a la "tesis de la aceptación" y de esto nos ocuparemos ahora.

Supongamos que pretendo ir al parque en auto. Sin embargo, leo una señal a la entrada del parque que dice: "No está permitido estacionar los vehículos en el parque". Giro el volante de mi vehículo, retrocedo y me estaciono unas pocas calles más allá. Usted me pregunta por qué giré el volante de mi vehículo, retrocedí y me estacioné unas pocas calles más allá del parque. Respondo que llevé a cabo esas acciones porque hay una regla que dice "no está permitido estacionar los vehículos en el parque". De acuerdo con la "tesis de la aceptación", mi deseo de seguir el patrón de conducta indicado por la regla y mi creencia de que girar el volante de mi vehículo, retroceder y no estacionar en el parque es el tipo de acción o patrón de conducta indicado por la regla. Sin embargo, supongamos que deseo evitar estacionar en el parque y tengo la creencia respectiva. En otras palabras, acepto "no estacionar en el parque". En mi camino hacia el par- 
Rastreando las críticas de Finnis al punto de vista interno de Hart: inestabilidad...

que, sin embargo, mientras sigo las instrucciones para llegar allí, tomo un giro equivocado y termino estacionando justo fuera de la entrada del parque. Aun cuando los dos criterios de la "tesis de la aceptación" se han cumplido, este no fue un caso de seguir la regla legal por aceptación, dado que cumplí la regla por accidente.

El problema con la "tesis de la aceptación" es que no considera la acción desde el punto de vista deliberativo, es decir, cómo es vista desde el punto de vista del agente o persona que delibera. En la autocomprensión de sus propias acciones, el agente no examina sus propias acciones mentales, más bien mira hacia afuera, hacia el vehículo, el parque, la señal, etc. Las razones para la acción, es decir, girar el volante, luego estacionar fuera del parque para seguir la regla, son autoevidentes o transparentes para él. Pero entonces, podría decir un objetor, ¿cuál es la característica benéfica de una regla que es el objetivo de la acción de evitar estacionar en el parque? Mi respuesta es la siguiente: cuando al conductor se le pregunta por qué está girando el volante y retrocediendo el vehículo, su respuesta será "porque es la regla". Pero esto no es todavía completamente inteligible a menos que nosotros asumamos o sepamos que el conductor es un ciudadano respetuoso del derecho o que cree en la imparcialidad general de las normas jurídicas, etc. Podemos continuar preguntándole “ipor qué, a causa de la regla, hiciste eso?” Su respuesta necesitaría estar en los términos de las razones como características benéficas para él, en orden a hacer inteligible su acción intencional. Probablemente responderá que tiene razones para seguir la norma jurídica porque es la mejor manera de preservar la paz del parque, o que tiene razones para seguir las normas jurídicas en general porque es la mejor manera de preservar la coordinación ${ }^{24}$ entre los miembros de una comunidad. Para decirlo en pocas palabras, el agente o persona que delibera necesita probar que las razones para la acción en términos de características benéficas y el objetivo o razón de la acción proveen la forma inteligible de la acción.

Además, en regímenes benévolos o malignos, si seguimos el modelo de Hart, los funcionarios del gobierno critican cualquier desviación de las reglas y esperan la obediencia a las mismas como estándar, pero podemos

${ }^{24}$ Véase, para un argumento de la autoridad como una necesidad práctica, Anscombe (1981). 
observar el mismo patrón de conducta oficial tanto en regímenes malignos como en los benévolos. Así, en la metodología de Hart no somos capaces de diferenciar entre regímenes malignos y benévolos, o esta diferenciación deviene irrelevante en tanto exista un patrón de conducta y cualquier desviación del estándar de conducta sea criticada. Esto parece paradójico, en la medida en que la mujer que se compromete con la inteligibilidad de la acción dentro del específico juego del lenguaje jurídico es capaz de hacer esta distinción básica, tal como se ilustra en el ejemplo "comprar y vender papas”. Pero el teórico equipado con la metodología de Hart no lo es. En consecuencia, la crítica del participante en la práctica social que se desvía del estándar es aleatoria, ininteligible y/o arbitraria porque no es guiada por el logos como características beneficiosas o valores que determinan la elección del participante.

La idea de la acción jurídica producida por un agente comprometido con el logos como características beneficiosas y que ejerce sus capacidades en circunstancias de contextos institucionales conocidos y juegos del lenguaje, contrasta agudamente con la idea de que comprendemos la acción jurídica mediante la aprehensión del patrón de acción que refleja la crítica de la desviación de la norma jurídica. La visión defendida por Hart reduce la riqueza del aspecto activo de las acciones del participante jurídico y ofrece un cambio de grado, pero no de tipo, de la pasividad representada por el derecho entendido como órdenes respaldadas por amenazas.

Un objetor podría alegar que podemos entender la aceptación de normas y acciones de los participantes en la práctica jurídica como un "punto de vista no comprometido", el cual no es ni deliberativo, ni teórico, sino más bien un "tercer punto de vista". Sin embargo, este "tercer punto de vista" es, como el deliberativo, un punto de vista práctico. La diferencia radica en el hecho de que se formula desde la perspectiva de una tercera persona. ${ }^{25}$

Siguiendo a Raz, el objetor podría decir que he presentado una interpretación muy restringida del punto de vista práctico y he reducido el

25 Siguiendo a Aquinas, podríamos decir que el "punto de vista no comprometido" es solo parcialmente deliberativo (práctico) y parcialmente teórico (2006d, I, q. 14, a. 16). Pero si es deliberativo, lo es solo en un sentido "secundario". He argumentado que el "punto de vista no comprometido" no es deliberativo en el sentido primario y por lo tanto no puede conducirnos a la acción (Rodríguez-Blanco, 2016, capítulo 5). 
Rastreando las críticas de Finnis al punto de vista interno de Hart: inestabilidad...

"punto de vista no comprometido" al punto de vista deliberativo. De acuerdo con Raz, el "punto de vista no comprometido" tiene dos rasgos centrales y debe ser caracterizado como sigue:

Primero, ellos son verdaderos o falsos si existe, en el sistema jurídico mencionado, una norma que requiera que la acción declarada sea una que debería realizarse; segundo, si la declaración es verdadera y la norma en virtud de la cual ella es verdadera y válida, uno debería ejecutar la acción, la cual, de acuerdo con la declaración, debería ser ejecutada legalmente. Tales declaraciones están muy generalizadas en los contextos jurídicos. Debe enfatizarse de nuevo que las declaraciones hechas desde un punto de vista o de acuerdo con un conjunto de valores son usadas en todas las esferas de la razón práctica, incluyendo la moralidad. Su uso está particularmente extendido cuando se discuten las razones y las normas que son ampliamente creídas y seguidas por una comunidad. Hay siempre gente que acepta el punto de vista y quiere saber qué se debe hacer de acuerdo con él en orden a conocer lo que deben hacer (1999, p. 177).

Pensemos primero sobre algunos ejemplos fuera del derecho, tal como los sugiere Raz. Si usted aconseja a un amigo que, por ejemplo, es vegetariano, de acuerdo con Raz usted no considera sus propias razones para la acción, sino más bien las razones de su amigo. Usted probablemente ama la carne, pero aconsejará a su amigo dentro del marco de su sistema normativo, es decir, su vegetarianismo.

Mi respuesta a esta objeción es la siguiente: en el ejemplo usado por Raz, ser vegetariano es bueno y usted le dice a su amigo, cuando va a un restaurante, que debe comer o las espinacas o el repollo (los únicos vegetales en el menú), porque ambos son cosas buenas para comer qua ser vegetariano y qua ser humano. En este ejemplo, usted puede decirle a su amigo "pide mejor el repollo, ya que eres vegetariano". No hay ninguna pregunta ulterior sobre por qué se ha impartido tal consejo. Lo bueno de comer o repollo o espinaca es obvio en el contexto. Así, está dado como una característica beneficiosa y es transparente para ambos. Sostengo que esto es parasitario desde el punto de vista deliberativo. El razonamiento podría ser el siguiente: 
(I) El repollo es bueno para los vegetarianos

Tú eres vegetariano

Hay repollo en el menú

¡Ordenemos repollo!

La dependencia o relación parasitaria del "tercer punto de vista" del punto de vista deliberativo es también clara en ejemplos muy diferentes de la premisa I. Franz Stangl ${ }^{26}$ era el comandante de Treblinka. Cuando fue nombrado por primera vez como jefe de una clínica de eutanasia, las acciones de los nazis le resultaron moralmente repelentes. Pero por aquel entonces temía perder su trabajo y su carrera. Comenzó a pensar que la eutanasia era un mal necesario y un favor que se hacía a los asesinados. Supongamos que Stangl era mi amigo en 1943 y que antes de que empezara su proceso de autoengaño me pidió que lo aconsejara sobre lo que debería hacer. De acuerdo con Raz, podría haberle respondido a Stangl: "según el sistema normativo del nacionalsocialismo, deberías seguir siendo el jefe de la clínica". Pero, de acuerdo con Raz, como un vegetariano que ha aceptado el marco normativo de ser vegetariano, Stangl ya ha aceptado el punto de vista normativo del nacionalsocialismo. Su pregunta es como la pregunta de un jugador de ajedrez: dadas las reglas del ajedrez, ¿cómo debería jugar? Ya ha aceptado la regla.

En respuesta a mi afirmación "de acuerdo con el derecho nazi, deberías permanecer como jefe de la clínica”, Stangl podría haber preguntado sensatamente “ ¿por qué debería?” El porqué está dirigido a la acción que he dado como consejo. Ha pedido consejo en términos de una razón para la acción, no solo en términos de una acción simpliciter, por ejemplo, una acción voluntaria que es realizada sin ninguna razón, y es necesario también que mi respuesta sea en los términos de razones para la acción. Cuando las personas buscan un consejo práctico están buscando razones. Los niños hacen esto todo el tiempo. Le preguntan a sus padres, maestros, familiares y amigos cómo hacer esto y lo otro. Aprenden que algunos fines son valiosos y dignos de ser perseguidos y otros no. Para dar consejo a Frank Stangl en términos de razones para la acción, como en el caso del amigo vegetariano,

${ }^{26}$ Ejemplo dado por Eleonore Stump (2003, p. 355) para explicar la interrelación entre intelecto y voluntad en Tomás de Aquino. Ver también Sereny (1983). 
Rastreando las críticas de Finnis al punto de vista interno de Hart: inestabilidad...

necesito una premisa como "(I) los vegetales son buenos". ¿Qué tipo de premisa puede jugar ese rol? Mi argumento es que solo una premisa que a) sea transparente y b) que describa la acción como una característica beneficiosa podría desempeñar ese rol. En ese caso, la premisa "la autoridad legítima es una cosa buena” puede jugar el rol de la premisa I. El razonamiento podría ser como sigue:

(II) La autoridad legítima es una cosa buena.27

El derecho nazi posee autoridad legítima.

Un oficial nazi ha ordenado que "deberías permanecer como jefe de la clínica de eutanasia".

¡Obedezcamos la orden!

Pero aquí mi consejo está equivocado. Sé que el derecho nazi no tiene autoridad legítima porque no es un caso de "autoridad legítima como una cosa buena". La segunda premisa es falsa. Es similar al caso de las vitaminas y las naranjas del modo siguiente:

La vitamina $C$ es buena para el sistema inmune.

La naranja sintética sin vitaminas es una cosa buena.

Tienes un resfriado, deberías estimular tu sistema inmune.

¡Comamos esta naranja sintética!

Como en el caso del derecho nazi, mi consejo está equivocado porque mi razonamiento es defectuoso dado que la segunda premisa es falsa. Stangl no tiene una razón para renunciar a su juicio. Si mi consejo se detiene al momento de expresar "desde el punto de vista jurídico, deberías obedecer el derecho", mi consejo está incompleto. Él puede demandar legítimamente razones para la acción, a saber, una respuesta a la pregunta por qué. Entonces necesito una premisa como I o II.

El tipo de compromiso activo con el derecho es fenomenológicamente distintivo. Hay crítica reflexiva no a causa de una desviación del estándar aceptado, sino más bien porque una violación de las normas jurídicas socava el logos como valores o características beneficiosas que subyacen a la

27 Como Geach (1956), uso "buena" como un adjetivo atributivo, en lugar de un predicado atributivo. 
norma jurídica o al derecho en general. Para Finnis, socava el objetivo del bien común que el derecho pretende alcanzar. La complejidad del aspecto activo del derecho implica un cambio en el tipo y no puede aprehenderse por los dos rasgos clave del aspecto interno esbozados por Hart. En consecuencia, para Finnis existe la necesidad de una manera más compleja de identificar la acción que se compromete con el derecho.

\section{Conclusiones}

Durante los últimos cincuenta años los debates de la filosofía del derecho en el mundo de habla inglesa se han concentrado en la crítica de Dworkin a El Concepto de Derecho de Hart, incluyendo la muy debatida distinción entre los desacuerdos semánticos y teóricos. A mi parecer, esta concentración de recursos intelectuales en un solo debate ha tenido lugar a costa de comprender una crítica de Finnis más llamativa y perspicaz, la cual habría conducido a la filosofía del derecho a un ámbito de investigación sobre la razón práctica y la teoría de la acción en el derecho. Podría decirse que los debates sobre ética normativa no pueden entenderse sólidamente sin entender qué es la acción y más específicamente qué son las acciones correctas y buenas. Si la crítica de Finnis hubiera sido tomada en serio, los teóricos del derecho habrían estado a la vanguardia en los debates sobre las cuestiones normativas y se habría ganado mucha claridad sobre la naturaleza del derecho y su relación con la acción, las razones para la acción y lo bueno.

Finnis nos dice que el participante de la práctica jurídica — por ejemplo, el ciudadano, el juez, el abogado- está comprometido con el derecho y está interesado en distinguir entre una norma buena y una norma no tan buena, entre una directiva justa y una directiva injusta, entre una decisión racional de un tribunal y una decisión irracional. El punto de vista interno de Hart se niega a hacer más distinciones entre los casos periféricos y centrales del derecho y esto trae inestabilidad al concepto.

El punto de vista interno de Hart como inestable puede remontarse a una crítica más fundamental, a saber, el punto de vista interno de Hart no puede usarse para entender el sentido y propósito de las acciones humanas 
Rastreando las críticas de Finnis al punto de vista interno de Hart: inestabilidad...

y por lo tanto no podemos contar con el punto de vista interno de Hart para identificar diferencias significativas que pueda hacer cualquier actor en el campo. En la literatura sobre la "metodología", esta discusión sobre la inestabilidad es pasada por alto y sus premisas no han sido examinadas cuidadosamente. En este capítulo, he mostrado las premisas que explican la idea de que el punto de vista interno es inestable, lo cual es clave tanto para comprender los límites de la teoría del derecho de Hart como para arrojar más luz sobre la opinión de la que el derecho debe concebirse en términos de un caso central o focal.

En el corazón de la investigación de Finnis se encuentra la cuestión práctica de lo que se debe hacer de acuerdo con los principios de la razonabilidad práctica. Para Finnis, el teórico necesita explicar el punto de vista práctico, pero una vez que el punto de vista práctico ha sido identificado nos afecta a todos: al teórico y al participante.

La comprensión completa de las acciones y las prácticas implica una comprensión del sentido y propósito de la acción o práctica. El agente que ejecuta la acción o el participante que participa en la práctica le da a la acción o práctica su sentido y propósito o valor.

He mostrado que el punto de vista interno de Hart depende de una concepción defectuosa de la acción humana que depende de los estados mentales, esto es, las creencias, los deseos, las actitudes, que causan las acciones. El estudio demuestra que esta teoría no puede explicar el sentido y propósito de la acción y de la práctica que Hart estaba tan ávidamente deseoso por enfatizar. He contrastado la concepción de la acción humana de Hart con la visión de Anscombe sobre la acción, que depende de la "metodología del porqué, de las razones como características beneficiosas y de las condiciones contextuales en las cuales aprendemos el logos de las prácticas sociales. Esto último ha iluminado el punto de Finnis de que solo si ubicamos al derecho en tanto que razón práctica como el caso central de derecho, somos capaces de identificar diferencias significativas que pueda hacer cualquier actor en el campo. 


\section{Bibliografía}

Adler, M. (2009). Social Facts, Constitutional Interpretation and the Rule of Recognition. En Adler, M. (ed.), The Rule of Recognition and the US Constitution (pp. 193-233). Oxford: Oxford University Press.

Annas, J. (1976). Davidson and Anscombe on the "same action". Mind, 85(338), 251-7.

Anscombe, E. (1981). Ethics, Religion and Politics: Collected Philosophical Papers of GEM Anscombe. Oxford: Blackwell.

Anscombe, E. (1963). Intention ( $2^{\mathrm{a}}$ ed.). Oxford: Blackwell.

Anscombe, E. (1958). Brute Facts. Analysis, 18(3), 69-72.

Aquinas, T. (2006a). Summa Theologiae (I-II, questions 6-17). Cambridge: Cambridge University Press.

Aquinas, T. (2006b). Summa Theologiae (I-II, questions 18-21). Cambridge: Cambridge University Press.

Aquinas, T. (2006c). Summa Theologiae (I, questions 75-83). Cambridge: Cambridge University Press.

Aquinas, T. (2006d). Summa Theologiae (I, questions 14-18). Cambridge: Cambridge University Press.

Blackburn, S. (1988). Ruling Passions. Oxford: Clarendon Press.

Chisholm, R. (1976). Freedom and Action. En Lehrer, K. (ed.), Freedom and Determinism (pp. 11-44). New York: Random House.

Coleman. J. (2001). The Practice of Principles. Oxford: Oxford University Press. Dancy, J. (2000). Practical Reality. Oxford: Oxford University Press.

Dickson, J. (2001). Evaluation and Legal Theory. Oxford: Hart Publishing. Davidson, D. (1963). Actions, Reasons and Causes. Journal of Philosophy, 60(23), 685-700.

Davidson, D. (1980). Essays on Actions and Events. Oxford: Clarendon Press.

Dworkin, R. (1986). Law's Empire. Cambridge: Harvard University Press.

Endicott, T. (2001). How to Speak the Truth, American Journal of Jurisprudence, 46, 229-248.

Finnis, J. (1987). On Reason and Authority in Law's Empire. Law and Philosophy, 6, 357-380.

Finnis, J. (1988). Moral Absolutes. Tradition, Revision and Truth. Washington D.C.: The Catholic University of America Press. 
Rastreando las críticas de Finnis al punto de vista interno de Hart: inestabilidad...

Finnis, J. (1998). Aquinas. Oxford: Oxford University Press.

Finnis, J. (2003). Law and What I Truly Should Decide, American Journal of Jurisprudence, 48, 107-129.

Finnis, J. (2011). Natural Law and Natural Rights (2 ed.). Oxford: Oxford University Press.

Gardner, J. (2001). Legal Positivism: 5 and 1/2 Myths. American Journal of Jurisprudence, 46(1), 199-227.

Geach, P. (1956). Good and Evil. Analysis, 17, 32-42.

Grisez, G. (1967). The First Principles of Practical Reasons: A Commentary on the Summa Theologiae, 1-2, Question 94, Article 2. Natural Law Forum, 10, 168-201.

Harman, G. (1986a). Change in View. Cambridge: MIT Press.

Harman, G. (1986b). Willing and Intending. En Grandy, R. and Warner, R. (eds.), Philosophical Grounds of Rationality (pp. 363-380). New York: Oxford University Press.

Hart, H. L. A. (1994). The Concept of Law. Oxford: Oxford University Press. Holton, R. (1998). Positivism and the Internal Point of View. Law and Philosophy, 17, 597-625.

Irwin, T. (1981). Homonym in Aristotle. The Review of Metaphysics, 34, 523-544.

Kenny, A. (1979). Aristotle's Theory of the Will. New Haven: Yale University Press. Moran, R. y Stone, M. (2009). Anscombe on Expression of Intention. En Sandis, C. (ed.), New Essays in the Explanation of Action (pp. 132-168). New York: Palgrave MacMillan.

Murphy, M. (2006). Natural Law in Jurisprudence and Politics. Cambridge: Cambridge University Press.

Patterson, D. (1999). Explicating the Internal Point of View, Southern Methodist University Law Review, 52, 67-74.

Perry, S. (2006). Hart on Social Rules and the Foundations of Law: Liberating the Internal Point of View. Fordham Law Review, 75, 1171-1209.

Perry, S. (2000). Holmes versus Hart: The Bad Man in Legal Theory. En Burton, S. (ed.), The Path of Law and Its Influence: The Legacy of Oliver Wendell Holmes, Jr. (pp. 158-196). Cambridge: Cambridge University Press.

Perry, S. (1995). Interpretation and Methodology in Legal Theory. En Marmor, A. (ed.), Law and Interpretation (pp. 97-135). Oxford: Clarendon Press. 
Raz, J. (1999). Practical Reason and Norms. Oxford: Oxford University Press. Rhonheimer, M. (2008). Perspective of the Acting Person: Essays in the Renewal of Thomistic Moral Philosophy. Washington D.C.: Catholic University of America Press.

Rodriguez-Blanco, V. and Zambrano. P. (2018). One Myth of the Classical Law Theory: Reflecting on the 'Thin' View of Legal Positivism. Ratio Juris, 31(1), 9-32.

Rodriguez-Blanco, V. (2016a). Law and Authority Under the Guise of the Good. Oxford: Hart-Bloomsbury.

Rodriguez-Blanco, V. (2016b). Action in Law's Empire. Canadian Journal of Law and Jurisprudence, 29(2), 431-456.

Rodriguez-Blanco, V. (2007). Is Finnis Wrong? Legal Theory, 13(3-4), 257-283.

Schauer, F. (1994). Fuller's internal point of view. Law and Philosophy, 13, 285-312.

Sereny, G. (1983). Into that Darkness. An Examination of Conscience. New York: First Vintage Book Editions.

Shapiro, S. (2006). What is the Internal Point of View? Fordham Law Review, 75, 1157-1170.

Shapiro, S. (2000). The Bad Man and the Internal Point of View. En Burton, S. (ed.), The Path of Law and Its Influence: The Legacy of Oliver Wendell Holmes, Jr. (pp. 158-196). Cambridge: Cambridge University Press.

Smith, M. (1994). The Moral Problem. Oxford: Blackwell.

Stump, E. (2003). Aquinas. London: Routledge.

Tollefsen, C. (2018). Aquinas Four Orders, Normativity and Human Nature. Journal of Value Inquiry, 52, 243-256.

Vogler, C. (2007). Modern Moral Philosophy Again: Isolating the Promulgation Problem. Proceedings of the Aristotelian Society, 106, 347-362.

Vogler, C. (2001). Anscombe on Practical Inference. En Millgram, E. (ed.), Varieties of Practical Reasoning (pp. 437-464). Cambridge, Mass.: MIT University Press.

Zambrano, P. (2015). Fundamental Principles, Realist Semantics and Human Action. Rechtstheorie, 46(3), 323-345.

Zipursky, B. (2006). Legal Obligations and the Internal Aspect of Rules. Fordham Law Review, 75, 1229-1253.

Wallace, J. (s. f.), "Practical Reason", Stanford Encyclopedia of Philosophy (http://plato.stanford.edu/). 